\title{
An NMR-Based Experimental Study on the Pore Structure of the Hydration Process of Mine Filling Slurry
}

\author{
Jielin Li $(\mathbb{D}$, Hanwen Liu $(\mathbb{D}$, Kaiming Ai, and Longyin Zhu \\ School of Resources and Safety Engineering, Central South University, Changsha, Hunan 410083, China \\ Correspondence should be addressed to Jielin Li; lijielin@163.com
}

Received 2 March 2018; Revised 26 June 2018; Accepted 10 July 2018; Published 13 August 2018

Academic Editor: Robert Černý

Copyright ( 2018 Jielin Li et al. This is an open access article distributed under the Creative Commons Attribution License, which permits unrestricted use, distribution, and reproduction in any medium, provided the original work is properly cited.

\begin{abstract}
To study the evolution of porosity in the process of filling slurry hydration, samples of tailing filling with different mixing ratios and different curing ages were prepared, and the pore structure was tested by low-field nuclear magnetic resonance (LF-NMR). According to the $\mathrm{T}_{2}$ spectrum distribution curve and $\mathrm{T}_{2}$ spectrum area of the filling slurry hydration process, the porosity and the evolution of the pore distribution features of the filling samples were analysed. The results showed that the higher the mass concentration of the filling slurry, the slower the hydration reaction, the smaller the average size of the pores, the higher the proportion occupied by harmful pores, and the lower the proportion occupied by multiharmful pores. The smaller the cementsand ratio of the slurry, the higher the proportion occupied by harmful pores and the larger the aperture of the pores. The porosity of the filling slurry with the cement-sand ratio of $1: 8$ is the highest, and the hydration velocity of the filling slurry with the cementsand ratio of $1: 3$ is the fastest.
\end{abstract}

\section{Introduction}

The mechanical properties of a filling body are critical factors ensuring the safe and efficient implementation of a filling mining method [1]. The filling slurry ratio and the microstructure characteristics of the filling are the main factors that influence the mechanical properties of the filling $[2,3]$. Therefore, studying the evolution of porosity in different proportions of filling slurry is of great practical value to the study of the stability of the filling body.

At present, research on the mechanical properties of backfill mainly focuses on macroscopic mechanics and optimization of proportioning; for example, Han et al. [4] studied the optimization of the mass fraction of different cementitious materials, the cement content, and the ratio of artificial sand to tailings and analysed the fluidity of the filling slurry and the strength of the filling. Fu et al. [5] obtained a cement tailing cemented filling body made and studied the relationships between the strength of the tailing cemented filling body and the mass fraction, the cementsand ratio, and the age of the slurry solid content. Based on the influence of the filling slurry microstructure on the mechanical properties of filled bodies, many scholars carried out intensive studies of the microstructure of filled bodies. Ke et al. [6] examined the influence of tailing particle size on the pore size distribution of the filling body by conducting experiments, and the results showed that the influence of the tailing grain size on the critical pore diameter decreases with an increase in the curing time, and the tailing grain size significantly affects the pore structure characteristics of the filling body. Ouellet et al. [7] used a scanning electron microscopy and image analysis (SEM-IA) method to research the pore structure of different proportions of cementfilled samples. Huang et al. [8] adopted phosphogypsum slag-based binding materials which were prepared from phosphogypsum, slag, cement clinker, and chemical activator. The hardening and hydration properties and mechanism of phosphogypsum slag-based binder were analysed by X-ray diffraction (XRD) and SEM. El-Hosiny [9] studied the effect of adding superplasticizer on the hydration and pore structure of slag cement slurry. Khalil [10] studied the changes in the pore specific surface area and the total porosity of cement pastes that contain different amounts of silica fume that occur with an increase in hydration time. 
The results show that, with the increase in hydration and the amount of silica fume, the ratio of the surface area to the total pore volume of wollastonite decreases. Xu et al. [11] used nuclear magnetic resonance (NMR) technology to study the pore size distribution and permeability of tailings under different hydraulic gradients and analysed their chemical composition and particle morphology by energydispersive spectroscopy (EDS) and XRD. She [12] studied the change in the cement slurry pore structure under nondamaged and noninvasive conditions using NMR. Yu and Chen [13] analysed the evolution of the pore structure of concrete after curing for 28 days, deduced the differential equation of mass and pore evolution, and established a new model of pore evolution. Liu et al. [14] analysed the bleeding rate and compressive strength of the tailing filling slurry and studied the improvement mechanism of special additives on the bleeding of slurry. The microstructure of the solidified body was analysed by SEM, EDS, and infrared spectroscopy (IR). Koohestani et al. [15] used mercury intrusion porosimetry (MIP), SEM, and uniaxial compressive strength testing to study the effect of maple wood sawdust addition on the mechanical properties and microstructure of cemented paste backfill (CPB). Studies have shown that the addition of $12.5 \%$ wood reduces the porosity and compactness of $\mathrm{CPB}$ materials.

The aforementioned studies mainly used XRD and SEM methods to study the pore structure of the filling body, or the main studying object was cement concrete. However, studies of the distribution and variation in the filling slurry pore structure in a mine have rarely been conducted. Low-field nuclear magnetic resonance (LF-NMR) is sensitive to water in the pores of rock and soil, and the curves of transverse relaxation time $\mathrm{T}_{2}$ obtained by LF-NMR were used to study the pore size distribution and the characteristics of microstructural change. Compared with SEM, CT, and other microscopic testing technologies [16], NMR has the advantages of simple operation, fast acquisition, and nondestructive testing. The disadvantage of NMR technology is that paramagnetic substances have a greater impact on the signal; for example, if a test sample contains more iron ions, the test process will be disturbed and the reliability of the results will be reduced. However, the mine filling slurry is a weak magnetic substance. In a very low-field condition, the few paramagnetic minerals within filling slurry cannot influence the measured results. Studies [11, 17-19] of pores and fractures of porous materials have shown that NMR can analyse the microstructural characteristics of porous materials. Therefore, in this paper, the microstructure and properties of filled slurry samples were studied by using the NMR technique, and the pore evolution of the samples under different curing ages and different proportions was analysed.

\section{Materials and Methods}

2.1. Materials. The sample materials for filling included cement, tailings, and water. The tailings were treated by the filter pressure, and they were taken from a mine in Guizhou, China. The cement used was P.C 32.5 cement from the
Fuhua cement plant in Changsha, China, and the water was tap water from the city of Changsha. Sieve analyses were applied to analyse the tailing particle size distribution, the cement particle size distribution was tested by a laser particle size analyser, and the chemical composition of tailings and cement was measured by X-ray fluorescence (XRF). The cement fineness was represented by the specific surface area, which was $968 \mathrm{~m}^{2} / \mathrm{g}$. The particle size distribution and main chemical composition are shown in Figure 1 and Table 1, respectively.

\subsection{Experimental Procedure}

2.2.1. Experimental Scheme. The concentration and sand ratio are two key factors that influence the mechanical properties of the filling body; therefore, the concentration and sand ratio were selected as the indexes for the experimental analysis. According to the particle size distribution of the tailings and engineering experience, three groups of experiments were conducted to analyse each factor: concentrations of $56 \%, 62 \%$, and $68 \%$ when the cement-sand ratio was $1: 3$ and cement-sand ratios of $1: 3,1: 5$, and $1: 8$ when the mass concentration was $56 \%$. The result (calculated by mass fraction) of the proportions of each sample is shown in Table 2.

2.2.2. Experimental Equipment. The microstructure tests for the filling slurry were conducted by the AniMR-150 NMR spectrometer manufactured by Suzhou NIUMAG Technology Co., Ltd. During the testing process, the prefabricated sample was placed at the centre of the RF coil, and a CPMG pulse sequence test was carried out. The CPMG test parameters were based on standard rock sample nuclear magnetic resonance parameters' laboratory measurement specifications (SY/T 6490-2014), and the detailed parameters are as follows: the value of the main frequency SF1 was $12 \mathrm{MHz}$; the value of the centre frequency $\mathrm{O} 1$ was $532,665.7 \mathrm{~Hz}$; the value of sampling point TD was 55,816; and the value of receiver bandwidth SW was $200 \mathrm{KHz}$. The value of the start sampling time, RFD, was adjusted according to the different sample signals. The value of the interval time, TW, was $3000 \mathrm{~ms}$. The value of the analog gain, RG1, was 15. The value of the digital gain, DRG1, was 3 . The value of the accumulate sample, NS, was 32 . The value of the $90^{\circ}$ pulse width, $\mathrm{P} 1$, was $19 \mu \mathrm{s}$. The value of the $180^{\circ}$ pulse width, $\mathrm{P} 2$, was $34 \mu \mathrm{s}$. The value of the semi-echo time, DL1, was $0.130 \mathrm{~ms}$, and the value of the echo number, NECH, was 1000 .

2.2.3. Experimental Steps. The samples were prepared according to Chinese national standards [20] and traditional practices. The detailed preparation process was as follows: (1) the tailings were placed in an electrothermal constanttemperature dryness box to dry for $24 \mathrm{~h}$ and then rolled with the wood roller, which facilitates the sieving of the tailings; (2) the rolled tailings were classified using a sieve with $0.5 \mathrm{~mm}$ aperture according to the particle size distribution of the tailings, and then the sieved tailings were selected as samples; 


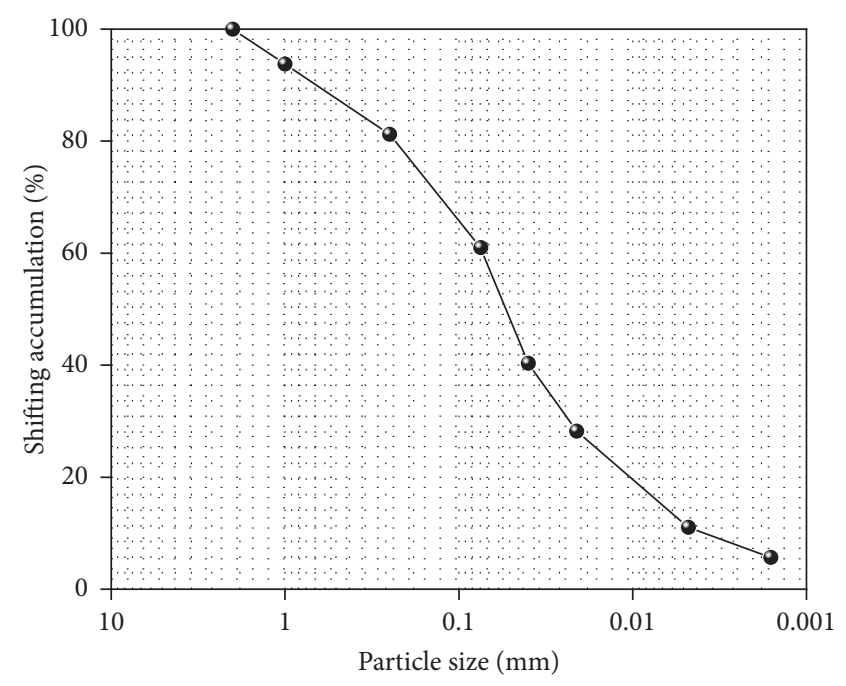

(a)

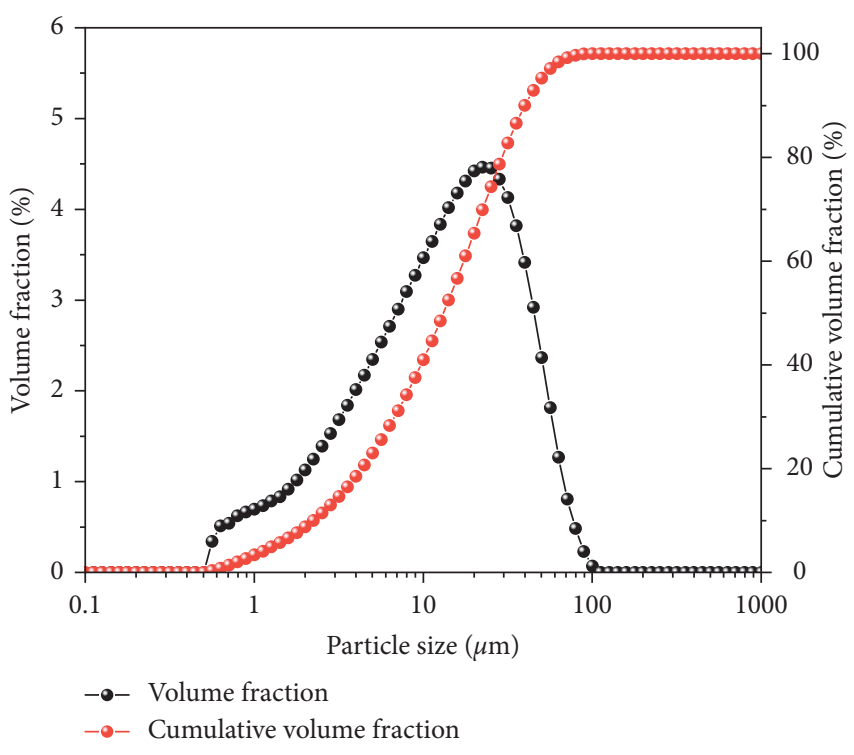

(b)

FIGURE 1: (a) Curve of tailing particle size distribution. (b) Cumulative grain and particle size distribution curve of cement.

TABLE 1: The chemical composition of the materials.

\begin{tabular}{lccccc}
\hline Materials & $\mathrm{SiO}_{2}$ & $\mathrm{CaO}$ & $\mathrm{MgO}$ & $\mathrm{Al}_{2} \mathrm{O}_{3}$ & $\mathrm{Fe}_{2} \mathrm{O}_{3}$ \\
\hline Tailings & 35.42 & 18.53 & 6.61 & 14.65 & 6.27 \\
Cement & 22.56 & 62.42 & 2.62 & 5.21 & 4.15 \\
\hline
\end{tabular}

TABLE 2: Proportion calculation of experimental specimens.

\begin{tabular}{lccccccccc}
\hline Cement-sand ratio & & $1: 3$ & $1: 3$ & $1: 3$ & & Cement-sand ratio & $1: 3$ & $1: 5$ & $1: 8$ \\
\hline \multicolumn{2}{l}{ Mass fraction of solid (\%) } & 56 & 62 & 68 & Mass fraction of solid (\%) & 56 & 56 & 56 \\
& Tailings & 42 & 46.5 & 51 & & Tailings & 42 & 46.67 & 49.78 \\
\multirow{2}{*}{ Mass fraction (\%) } & Cement & 14 & 15.5 & 17 & Mass fraction (\%) Cement & 14 & 9.33 & 6.22 \\
& Water & 44 & 38 & 32 & Water & 44 & 44 & 44 \\
\hline
\end{tabular}

(3) the quantities of tailings, cement, and water calculated by mass fraction were weighed by electronic balance with a degree of precision of $0.01 \mathrm{~g}$; (4) the prepared tailings, cement, and water were placed into a stainless steel pot and mixed evenly for $10 \mathrm{~min}$; (5) the mixed slurry was placed into a plastic bottle, which was sealed and labelled; and (6) the prepared samples were placed into a concrete curing box; the curing temperature was $20^{\circ} \mathrm{C}$, and the humidity was $99 \%$.

At curing times of $1 \mathrm{~h}, 3 \mathrm{~d}, 7 \mathrm{~d}, 14 \mathrm{~d}$, and $21 \mathrm{~d}$, the samples were taken out of the concrete curing box and subjected to NMR testing to obtain their $\mathrm{T}_{2}$ distribution curves, and the microstructure of the filling slurry was analysed. The experimental system and process are shown in Figure 2.

2.2.4. Experimental Method. Pore-related properties of filling slurry include the pore size, connectivity, open porosities, specific surface area, and distribution of pores $[21,22]$. Characterization methods of pore properties include SEM, CT, mercury intrusion, and nitrogen/carbon dioxide adsorption $[23,24]$. The drawbacks of these methods are slow data acquisition, inefficient testing, limited aperture range, and damage to samples [25]. NMR is a nondestructive, easy, and less time-consuming technology [26] which covers the widest aperture range (Figure 3 ). It has been applied in geological research, energy exploration, polymer materials, agriculture, life sciences, and so on.

NMR is the phenomenon whereby resonant transition of a nuclear core with a magnetic moment occurs due to electromagnetic waves in a constant magnetic field; the nuclear hydrogen atom in water molecules can generate an NMR phenomenon. NMR tests the pore size distribution inside the slurry by measuring the $\mathrm{H}$ protons in the pores of the slurry. The distribution curve of $\mathrm{T}_{2}$ and signal intensity can be obtained with NMR tests. According to the principle of NMR [27, 28], the relationship between the transverse relaxation time $\mathrm{T}_{2}$ and the specific surface area of pores can be described by the following equation:

$$
\frac{1}{\mathrm{~T}_{2}}=\rho \frac{S}{V}
$$

The pore radius is proportional to the pore throat radius [29], so (1) can be transformed into the following equation: 


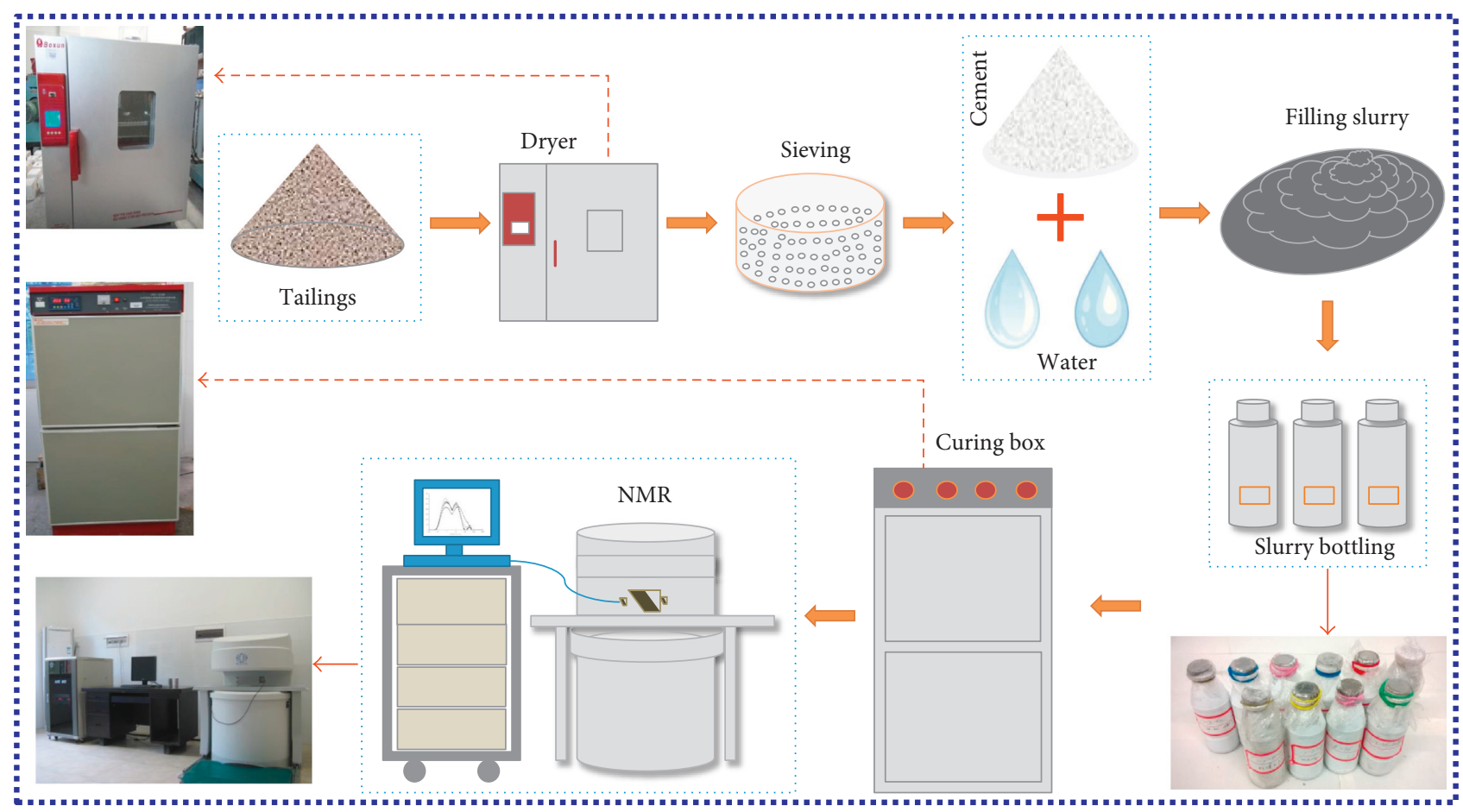

FIGURE 2: Experimental system and process.

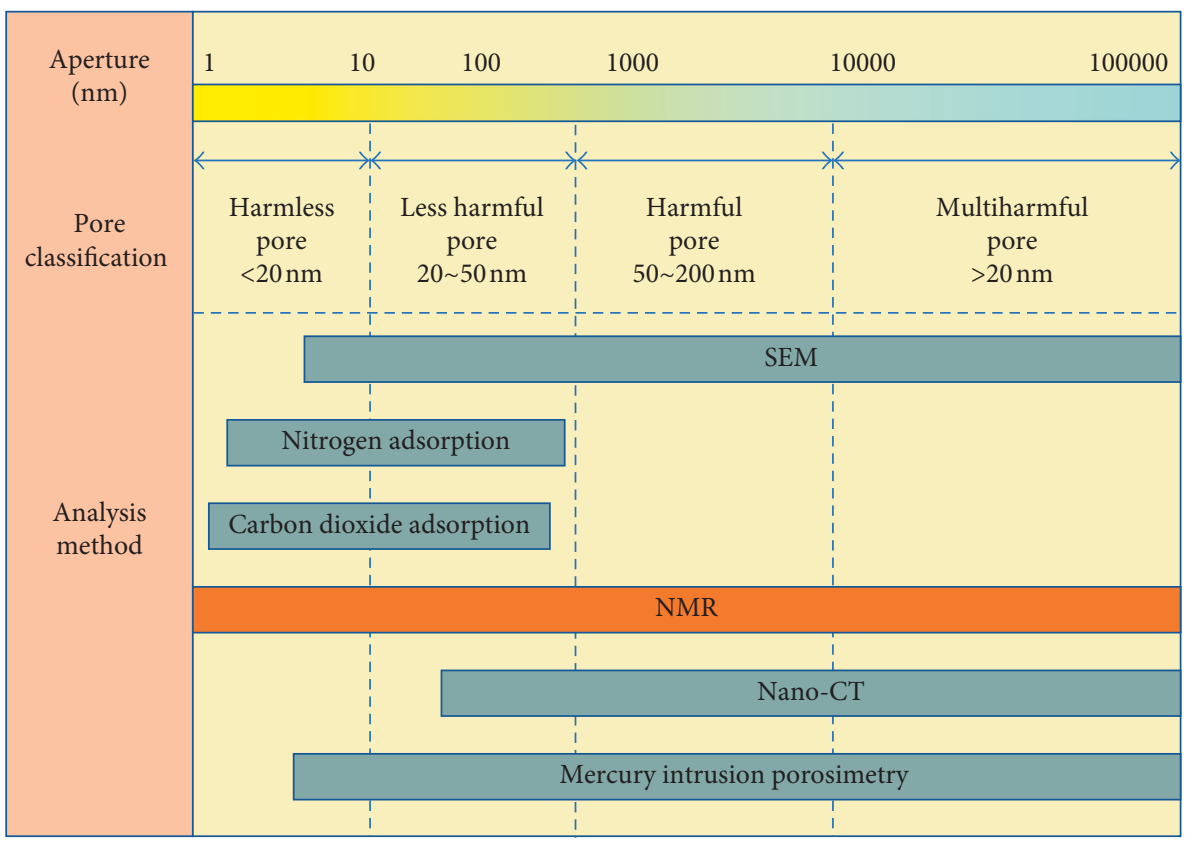

Figure 3: Aperture ranges $(\mathrm{nm})$ for filling slurry pore properties' characterization methods.

$$
\frac{1}{\mathrm{~T}_{2}}=F_{\mathrm{s}} \frac{\rho}{r}
$$

where $S$ is the surface area of the pore $\left(\mathrm{cm}^{2}\right) ; \rho$ is the surface relaxation strength $(\mu \mathrm{m} / \mathrm{ms}) ; V$ is the pore volume; $r$ is the pore radius; and $F_{\mathrm{s}}$ is a geometrical factor (for the spherical pores, $F_{s}=3$; for the columnar pores, $F_{s}=2$ ).
It can be concluded from (2) that the pore radius is in direct proportion to $\mathrm{T}_{2}$ : the smaller the $\mathrm{T}_{2}$ is, the smaller the represented pore becomes, and the larger the pore is, the larger the $\mathrm{T}_{2}$ becomes. Therefore, the relaxation time curve $\mathrm{T}_{2}$ of the sample can be transformed into the pore size distribution curve to obtain the pore size distribution of the filling slurry. $\mathrm{Wu}[30]$ proposed standards for the influence of different pore 
sizes on the strength of concrete. According to the standards, the pore size of filling slurry can be divided into four categories: harmless pores ( $<20 \mathrm{~nm}$, no influence on strength), less harmful pores $(20 \mathrm{~nm}-50 \mathrm{~nm}$, less influence on strength), harmful pores $(50 \mathrm{~nm}-200 \mathrm{~nm}$, influence on strength), and multiharmful pores $(>200 \mathrm{~nm}$, great influence on strength).

\section{Results and Analysis}

3.1. Effect of Concentration on Porosity Distribution in Filling Slurry. According to the hydration reaction equation of cement, when the concentration of filling slurry is in the range of $56 \%-68 \%$, the water consumed by hydration is approximately $40 \%$ of the weight of the cement [31]. The remaining water will be left in the pore filling slurry, and when the bleeding phenomenon is observed with the naked eye, it means that the pore filling slurry has been fully saturated. When the pores in the filling slurry are completely saturated, the surface area and volume of each pore are positively correlated with the value of the transverse relaxation time $\left(\mathrm{T}_{2}\right)$ of NMR. Therefore, the $\mathrm{T}_{2}$ distribution curve can be used to characterize the pore distribution characteristics of the filling slurry.

The size and number of the internal pores of the filling slurry will change in the hydration process. Because studies have not been conducted on the transverse relaxation rate $\rho$ of the filling slurry, accurate values cannot be obtained. Therefore, only approximate values of the materials can be referenced. As the mineral composition and material composition of the filling slurry are similar to those of concrete cement, the surface relaxation rate $\rho$ in the literature [12] is assumed to be $12 \mathrm{~nm} / \mathrm{ms}$.

According to the relationship between the pore radius and $\mathrm{T}_{2}$ in (2), the value of the pore geometry factor is 2 [29]; then, (2) can be simplified as

$$
r=24 \mathrm{~T}_{2} \times 10^{-9} .
$$

According to (3), the $\mathrm{T}_{2}$ spectra can be transformed into the pore size distribution curve. The pore size distribution of the filling slurries with mass concentrations of $56 \%, 62 \%$, and $68 \%$ is shown in Figure 4.

It can be seen from Figure 4 that the $\mathrm{T}_{2}$ distributions of the filling slurries with different concentrations mainly range from $0.1 \mathrm{~ms}$ to $10 \mathrm{~ms}$, and the $T_{2}$ distributions of filling slurries quickly shift to the left side within $7 \mathrm{~d}$, while they remain stable after $7 \mathrm{~d}$. The result reveals that the hydration reaction is rapid within the first $7 \mathrm{~d}$. This is because the hydration products that are produced by cement particles reacting with water will turn the macropores gradually into small pores. When the number of small pores increases, the flowing water decreases. With time, the bound water within the pores increases, and the hydration slows down, so that there are few changes in the $\mathrm{T}_{2}$ distribution of filling slurry after 7 days.

According to the classification standard of pore sizes, the $\mathrm{T}_{2}$ distribution curves of filling slurries with three different mass concentrations were segmented, and variations in the distribution ratios for different pore sizes with curing time were then obtained. They are shown in Figure 5.
As can be seen from Figure 5, three groups of tailing filling slurries with different mass concentrations are dominated by less harmful pores and harmful pores in the early stage. These two types of pores account for more than $80 \%$ of the volume of the total pores. In the later stage, harmless pores and less harmful pores dominate, accounting for approximately $90 \%$ of all the pores. After $3 \mathrm{~d}$ of curing, the proportion of less harmful pores increased significantly, while the proportion of harmful pores dropped significantly. This phenomenon indicates that harmful pores turned into less harmful pores gradually, which indicates that the filling slurry hydration reacted quickly within $3 \mathrm{~d}$, and the pore size became smaller. As the curing time increased, the proportion of harmless pores increased gradually, the proportion of harmful pores decreased continuously, and the proportion of less harmful pores tended to remain stable at approximately $70 \%$ after $3 \mathrm{~d}$.

In addition, it can be seen from Figure 5 that the changes in the proportion of pores with different pore diameters in the filling slurries with three different concentrations were small after $7 \mathrm{~d}$, which means that the filling slurry hydration reaction was basically stabilized after $7 \mathrm{~d}$. Comparing the pore size distribution statistics of three different concentrations of filling slurries with different curing times, the change in mass concentration within one hour had little effect on the pore size distribution of each filling slurry. However, as the mass concentration increased, the growth rate of harmless pores increased with curing time and the reduction rate of harmful pores also increased. After $21 \mathrm{~d}$, the proportion of harmful pores in the filling slurry with the mass concentration of $68 \%$ was close to 0 . It should be noted that as the mass concentration increased, the proportion of less harmful pores changed in different directions as the curing time increased. In the filling slurry with the mass concentration of $56 \%$, the proportion of less harmful pores increased slowly, whereas it reduced gradually in the filling slurry with the mass concentration of $68 \%$, which indicates that the greater the mass concentration, the smaller the proportion of harmful and multiharmful pores, and that this scenario is conducive to increasing the stability of the filling body.

\subsection{Effect of the Cement-Sand Ratio on the Pore Distribution of} Filling Slurry. The $\mathrm{T}_{2}$ and pore size distributions of the filling slurries with cement-sand ratios of $1: 3,1: 5$, and $1: 8$ are shown in Figure 6. The $\mathrm{T}_{2}$ distributions of the filling slurries contain one main peak and two subpeaks. The distributions of $T_{2}$ of the slurries with cement-sand ratios of $1: 3$ and $1: 8$ mainly ranged from $0.1 \mathrm{~ms}$ to $10 \mathrm{~ms}$, whereas the distribution of $\mathrm{T}_{2}$ of the slurry with the cement-sand ratio of $1: 5$ mainly ranged from $0.1 \mathrm{~ms}$ to $10 \mathrm{~ms}$. This phenomenon indicates that small-size pores were more abundant in the filling slurries with cement-sand ratios of $1: 3$ and $1: 8$ than in the filling slurry with the cement-sand ratio of $1: 5$. As the curing time increased, the $\mathrm{T}_{2}$ distribution of the filling slurries moved toward the left side. These curves moved rapidly in the first $3 \mathrm{~d}$ and then slowed down from 3 to $7 \mathrm{~d}$, and the left shift became inconspicuous after $7 \mathrm{~d}$. Moreover, 


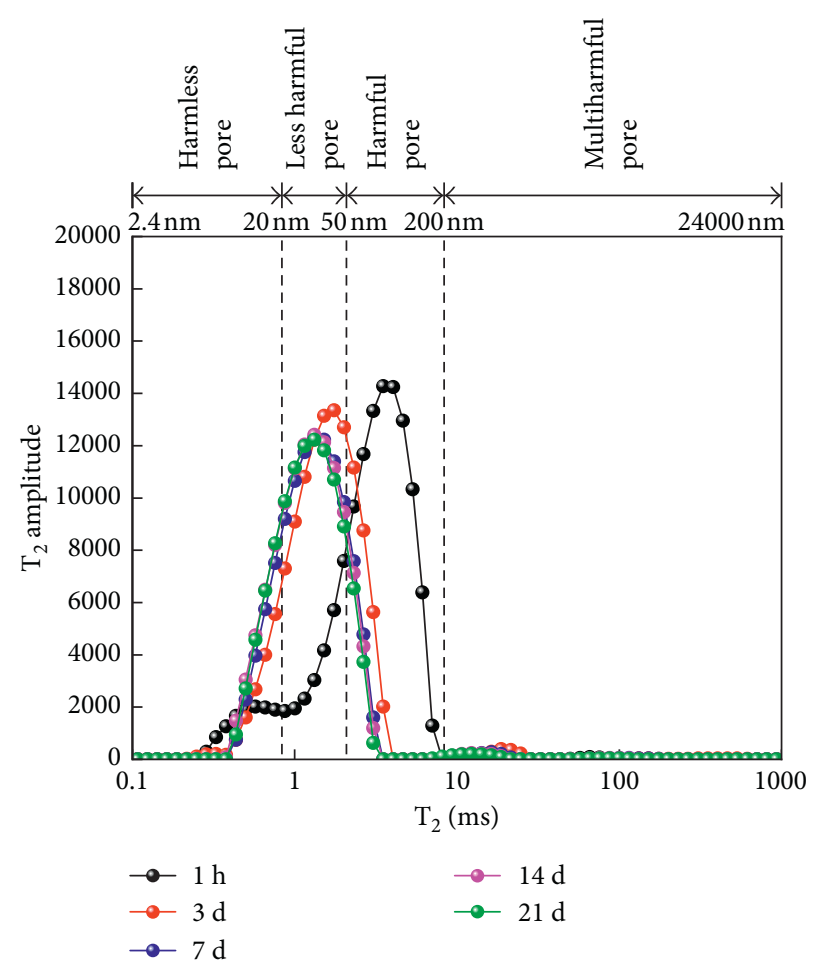

(a)

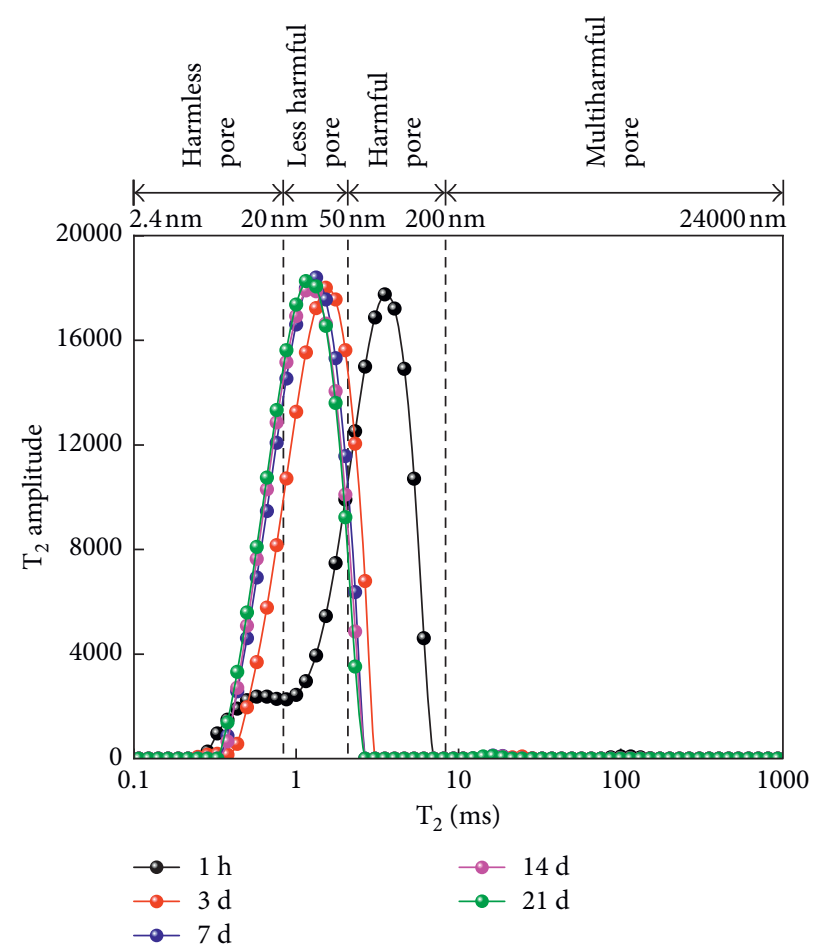

(b)

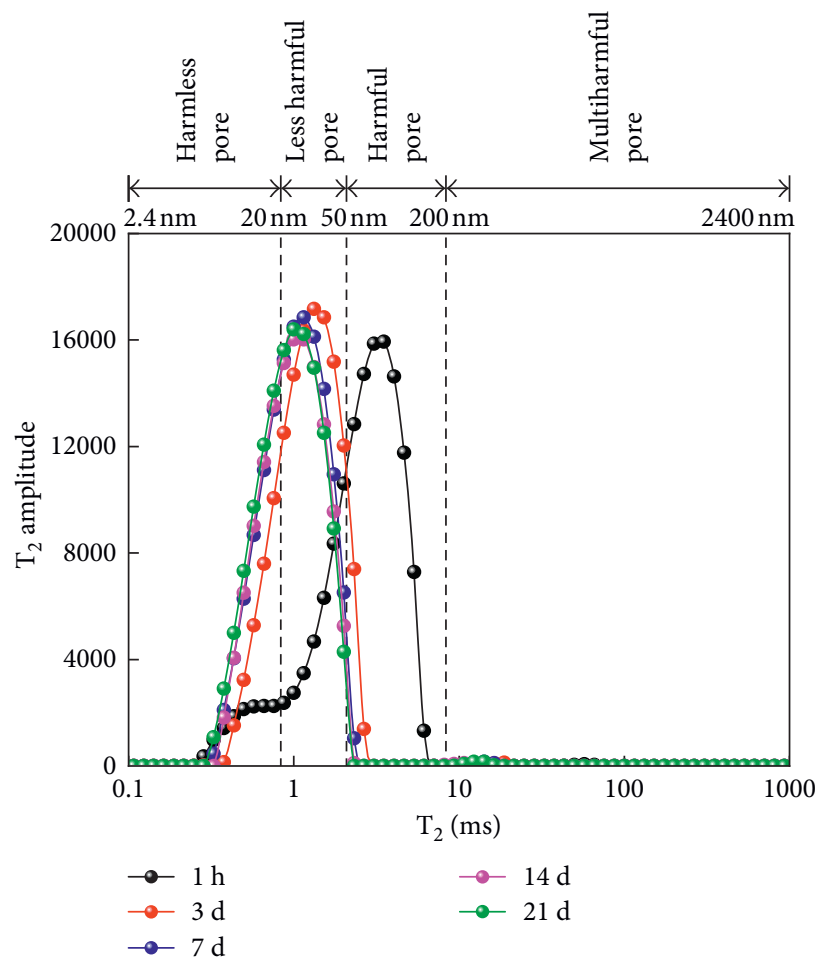

(c)

FIgURE 4: The $\mathrm{T}_{2}$ curve and pore size distributions of the filling slurries with different concentrations: (a) 56\%, (b) 62\%, and (c) 68\%.

when the cement-sand ratio decreased, the extent of the left shift of the $\mathrm{T}_{2}$ distribution decreased gradually, which indicates that the hydration reaction rates of the filling slurries decreased gradually with an increase in curing time.
Additionally, the generated hydration products were fewer, resulting in a decrease in pores, which were becoming smaller. After $7 \mathrm{~d}$, the hydration process of the filling slurry was almost complete, and the greater the cement-sand ratio, the faster the 


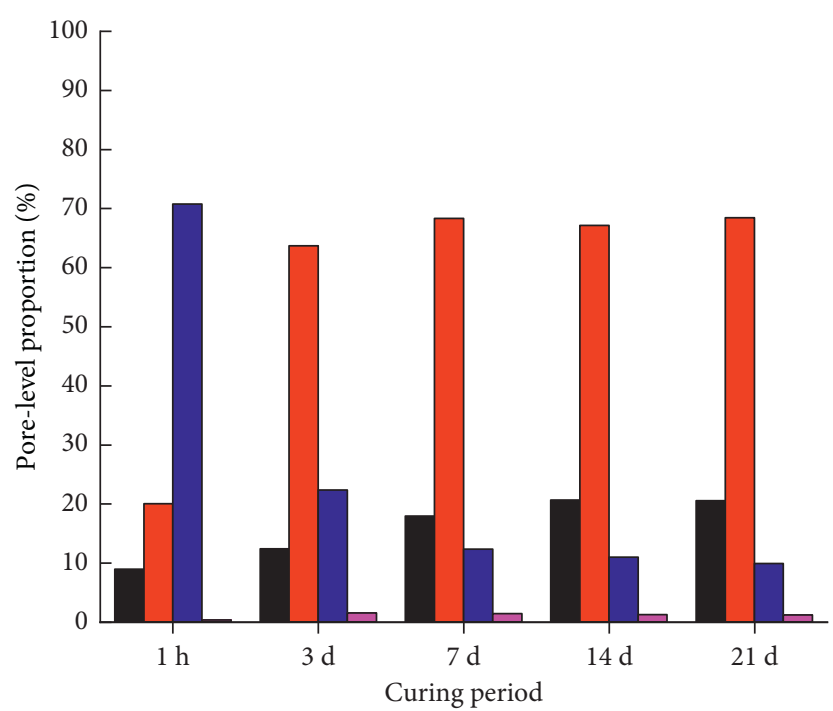

Harmless pore Harmful pore $\square$ Less harmful pore
$\square$ Multiharmful pore

(a)

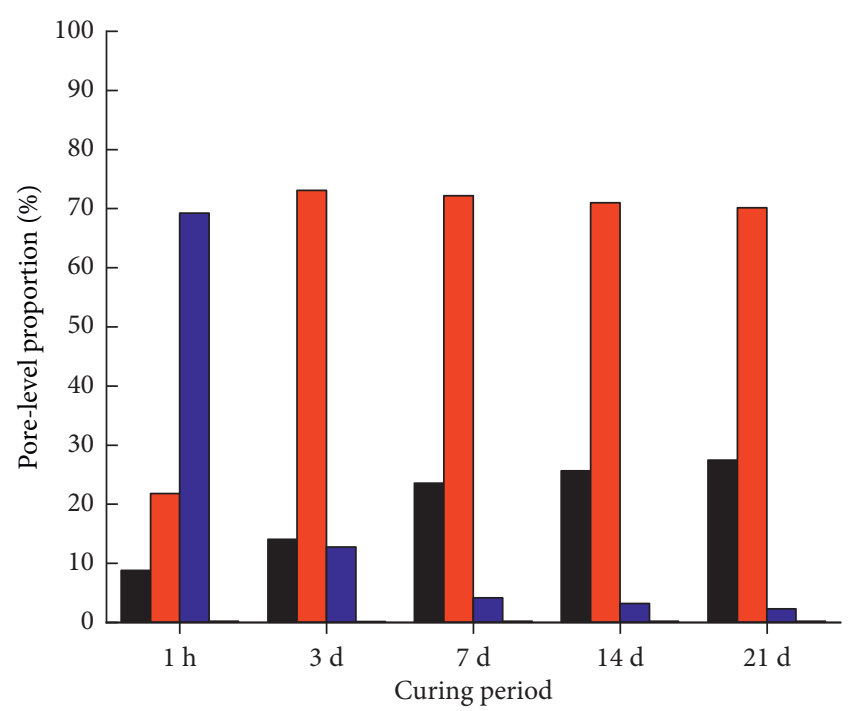

Harmless pore Harmful pore

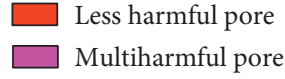

$\square$ Less harmful pore
Multiharmful pore

(b)

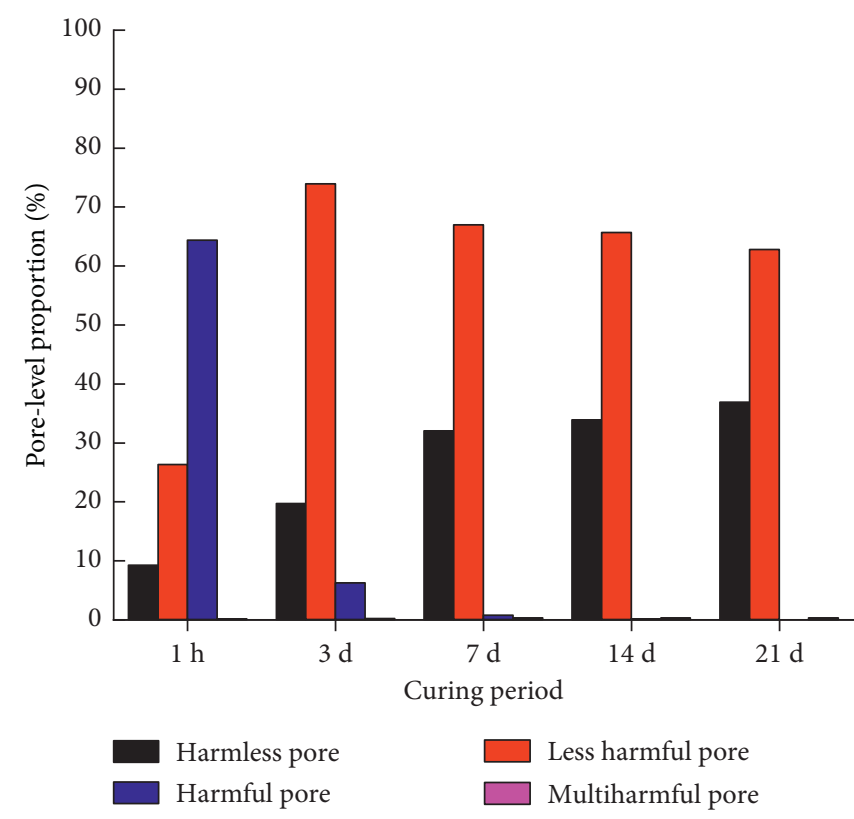

(c)

FIgURE 5: Pore size distributions of the filling slurries with different concentrations: (a) 56\%, (b) 62\%, and (c) $68 \%$.

hydration reaction. It can also be seen from Figure 6 that the pore size of the filling slurries with cement-sand ratios of $1: 3$ and $1: 5$ was mainly dominated by less harmful pores and harmful pores, whereas for the filling slurry with the cementsand ratio of $1: 8$, multiple harmful pores appeared in the early stage and gradually disappeared after $3 \mathrm{~d}$.

By counting the three groups of $\mathrm{T}_{2}$ distribution curves of the filling slurries at different subsections, the changes in the distribution of different pore ratios with changes in the concentration and curing time can be seen in Figure 7 .

As Figure 7 shows, in the early stage, the three groups of tailing filling slurries mainly consisted of harmful pores, whose volume accounted for more than $70 \%$ of the total pore volume. In the later stage, the filling slurry with the cementsand ratio of $1: 3$ was dominated by harmless pores and less harmful pores, and less harmful pores and harmful pores were the dominant pores of the filling slurries with cementsand ratios of $1: 5$ and $1: 8$, accounting for more than $80 \%$ of the total pore volume. As the curing time increased, the increase in the proportion of less harmful pores and the reduction in the proportion of harmful pores decreased, which means that the harmful pores gradually turned into less harmful pores. The filling slurry with the cement-sand ratio of $1: 3$ had the largest change within $3 \mathrm{~d}$, but the change 

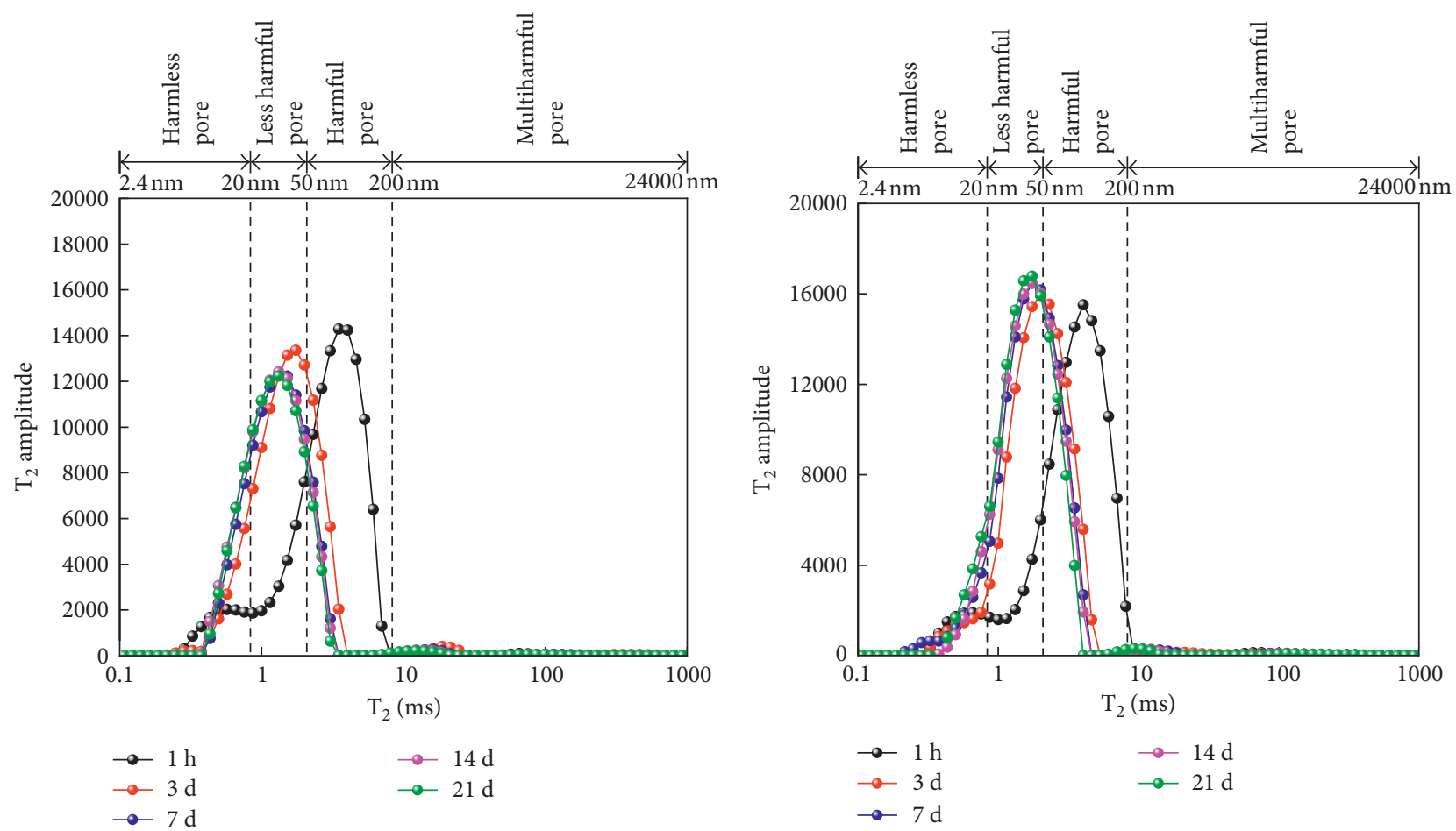

(a)

(b)

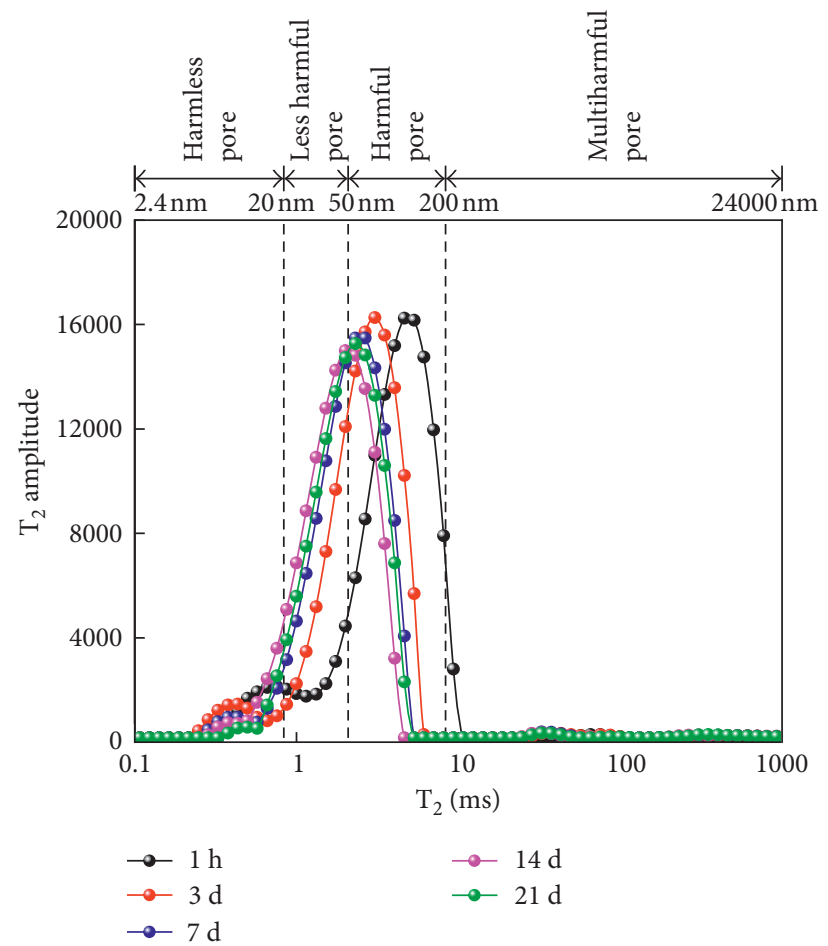

(c)

FIgURE 6: $T_{2}$ curves and pore size distributions of the filling slurries with different cement-sand ratios: (a) $1: 3$, (b) $1: 5$, and (c) $1: 8$.

gradually flattened after $3 \mathrm{~d}$. However, the changes in the filling slurries with cement-sand ratios of $1: 5$ and $1: 8$ were small after $7 \mathrm{~d}$, which indicates that the delay time of the filling slurry hydration reaction increased as the cementsand ratio decreased.
Comparing the statistics of aperture classification for the three kinds of filling slurries after different curing times, the less harmful pores and harmful pores were mainly affected by the cement-sand ratio within $1 \mathrm{~h}$. The smaller the cementsand ratio, the lower the proportion of less harmful pores and 


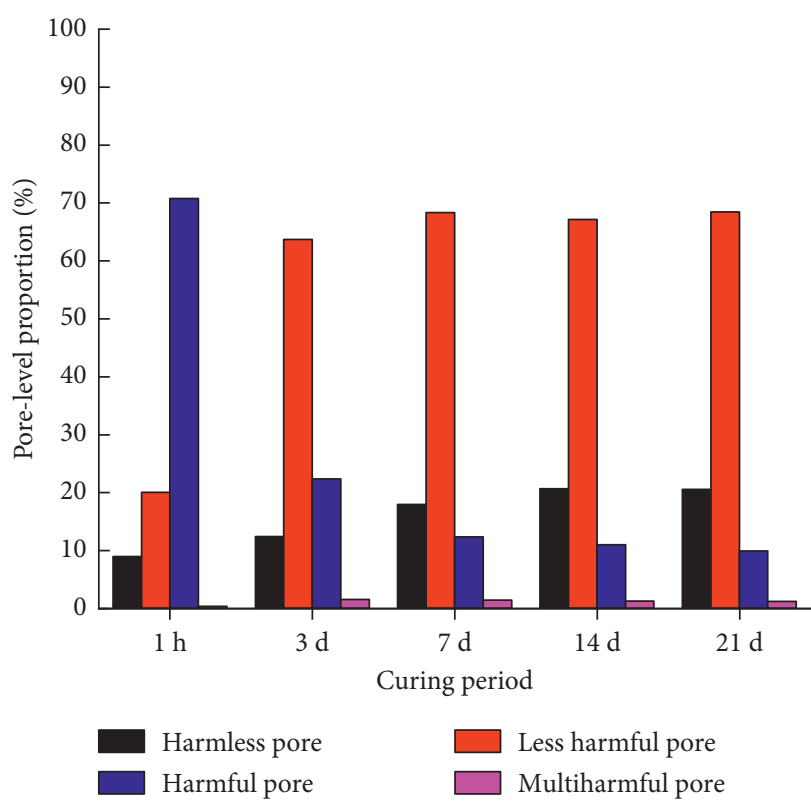

(a)

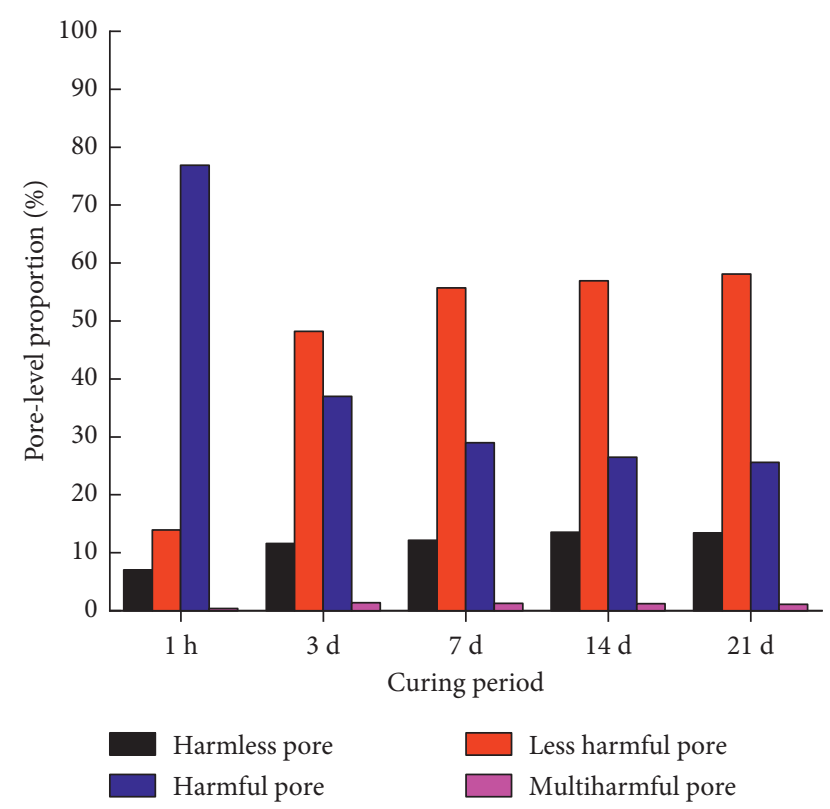

(b)

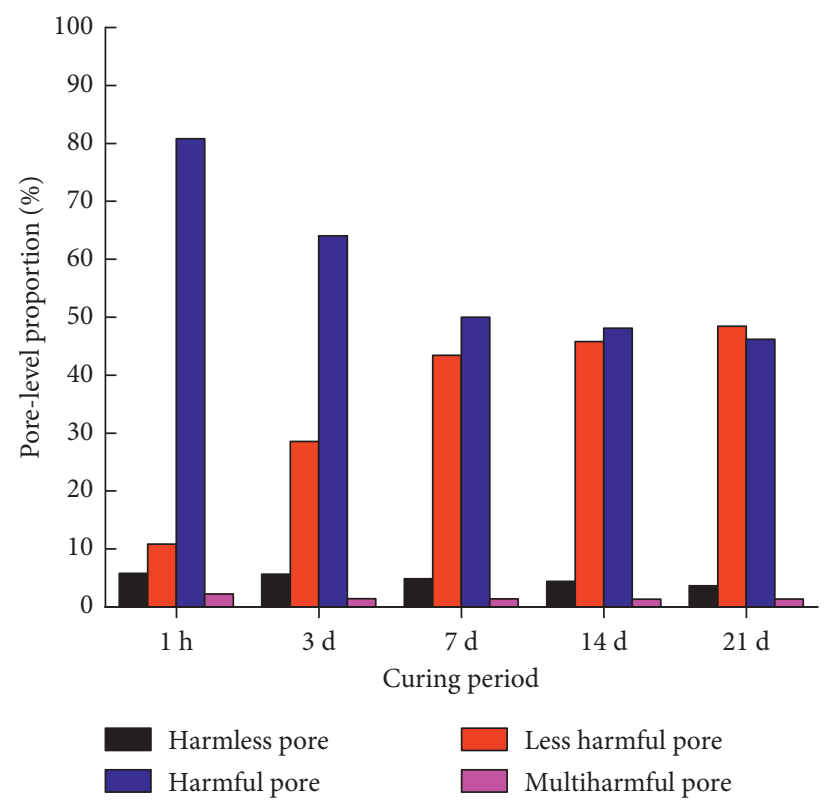

(c)

Figure 7: Pore size distributions of the filling slurries with different cement-sand ratios: (a) $1: 3$, (b) $1: 5$, and (c) $1: 8$.

the higher the proportion of harmful pores within $1 \mathrm{~h}$. As the hydration proceeded, the increase in the harmless and less harmful pores decreased as the cement-sand ratio decreased, and the reduction in harmful pores decreased as the cementsand ratio decreased. When the curing time reached $21 \mathrm{~d}$, the filling slurry with the cement-sand ratio of $1: 3$ mainly contained less harmful pores and harmless pores, with harmful pores being the most dominant, whereas the filling slurries with cement-sand ratios of 1:5 and 1:8 mainly contained less harmful pores and harmful pores, with less harmful pores being the most dominant. Furthermore, the proportion of less harmful pores was approximately the same as that of the harmful pores in the filling slurry with the cement-sand ratio of $1: 8$. This shows that the smaller the cement-sand ratio, the larger the proportion of harmful pores, which is not conducive to the stability of the filling body.

\section{Discussion}

4.1. $T_{2}$ Spectrum Area Change. The size of the $\mathrm{T}_{2}$ spectrum is proportional to the amount of fluid contained in the sample, which is related to the porosity of the sample. The $T_{2}$ spectrum of filling slurry under different conditions directly reflects the change in the pores in the filling slurry hydration process.

Figure 8 shows the $T_{2}$ spectrum area of three kinds of slurries with different mass concentrations and cement-sand 


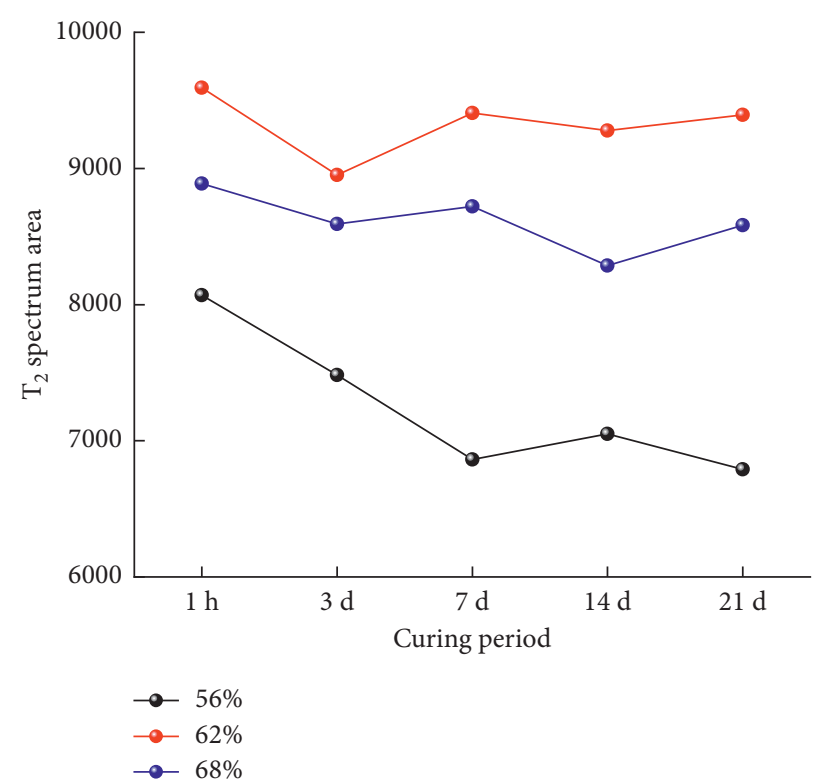

(a)

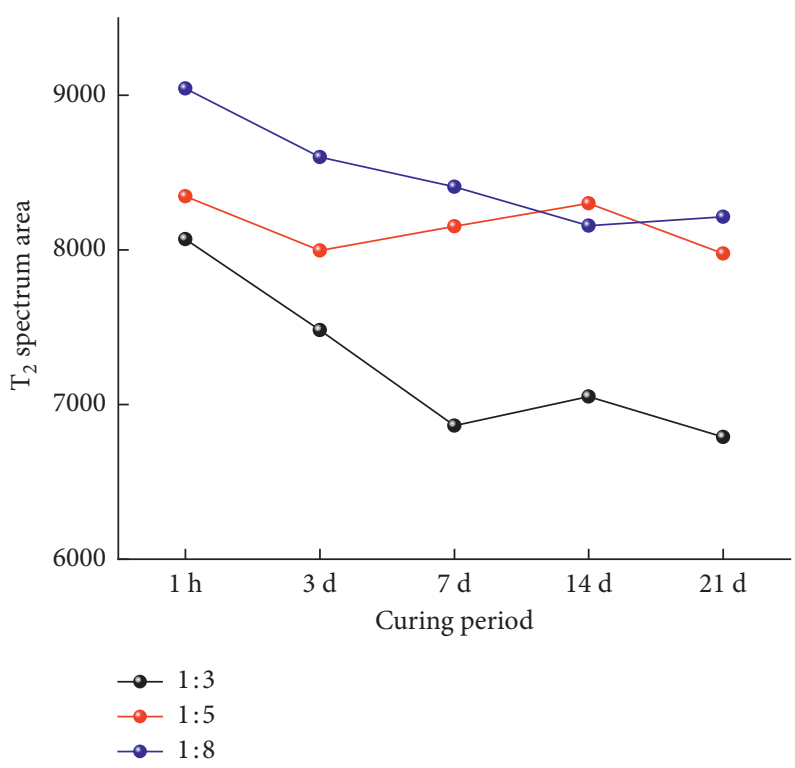

(b)

Figure 8: (a) The $\mathrm{T}_{2}$ spectrum area of three kinds of filling slurries with different concentrations and curing periods. (b) The $\mathrm{T}_{2}$ spectrum area of three kinds of filling slurries with different cement-sand ratios and curing periods.

ratios. It can be seen from Figure 8 (a) that the $\mathrm{T}_{2}$ spectrum area decreases gradually as the curing time increases, especially for the filling slurry with the mass concentration of $56 \%$. For the three kinds of filling slurries with different mass concentrations, the $\mathrm{T}_{2}$ concentration of the filling slurry with the mass concentration of $62 \%$ is the largest, followed by that of the filling slurry with the mass concentration of $68 \%$, and the smallest $\mathrm{T}_{2}$ concentration was observed in the filling slurry with the mass concentration of $56 \%$. This indicates that the $\mathrm{T}_{2}$ spectrum area does not increase with an increase in concentration. Thus, the mass concentration is not the only factor that affects the porosity of the filling slurry.

In Figure $8(\mathrm{~b})$, the $\mathrm{T}_{2}$ spectrum area of the three filling slurries with different ratios of cement-sand gradually decreases with an increase in curing time, indicating that curing time has an influence on the porosity of the filling slurry. With the decrease in the cement-sand ratio, the spectrum area gradually increases, indicating that the filling slurry porosity will increase with a decrease in the cementsand ratio. With a decrease in the cement-sand ratio, the change extent of the spectrum area reduced, which indicates that the hydration rate of the slurry with the cement-sand ratio of $1: 3$ is the fastest, whereas that of the filling slurry with the cement-sand ratio of $1: 8$ is the slowest, leading to different porosity change results.

\subsection{Effect of Filling Slurry Hydration on Pore Structure.} The main components of tailing slurry are cement, tailings, and water. Changes in the hydration reaction of cement, tailings, and water, resulting in the formation of water compounds and leading to a change in porosity, are primarily responsible for changes in the pore structure of the tailing slurry. Therefore, from the perspective of hydration reactions, the mechanism of the pore structure evolution of tailing slurry is discussed:

(1) The hydration reaction in the filling slurry of tailings mainly includes the hydration of tricalcium silicate, dicalcium silicate, tricalcium aluminate, and ironbased solid solutions [32]. The hydration process of tricalcium silicate hydrate and dicalcium silicate hydrate has a decisive influence on the composition of the hydrate and the structure of filling slurry [33]. The hydration reaction equations of tricalcium silicate and dicalcium silicate hydration are as follows:

$$
\begin{aligned}
& 3 \mathrm{Cao} \cdot \mathrm{SiO}_{2}+n \mathrm{H}_{2} \mathrm{O} \\
& =x \mathrm{CaO} \cdot \mathrm{SiO}_{2} \cdot y \mathrm{H}_{2} \mathrm{O}+(3-x) \mathrm{Ca}(\mathrm{OH})_{2} \\
& 2 \mathrm{CaO} \cdot \mathrm{SiO}_{2}+n \mathrm{H}_{2} \mathrm{O} \\
& \quad=x \mathrm{CaO} \cdot \mathrm{SiO}_{2} \cdot y \mathrm{H}_{2} \mathrm{O}+(2-x) \mathrm{Ca}(\mathrm{OH})_{2}
\end{aligned}
$$

In addition, the tailings and cement contained a small amount of $\mathrm{MgO}$, and $\mathrm{MgO}$ also had a slow chemical reaction with water [34-36]:

$$
\mathrm{MgO}+\mathrm{H}_{2} \mathrm{O}=\mathrm{Mg}(\mathrm{OH})_{2}
$$

The hydration of tricalcium silicate hydrate was similar to the hydration of dicalcium silicate, but the hydration reaction of dicalcium silicate was slower, and less $\mathrm{Ca}(\mathrm{OH})_{2}$ was generated [37]. Figure 5 shows that the $\mathrm{T}_{2}$ spectrum area changes in filled slurries within $3 \mathrm{~d}$ with mass concentrations of $56 \%$ and $62 \%$ were more obvious than that in the filling slurry with $68 \%$ mass concentration; that is, the filling slurries with mass concentrations of $56 \%$ and $62 \%$ were more 
rapidly hydrated. It is likely that as the concentration increased, the hydration reaction gradually changed from the hydration of tricalcium silicate to the hydration of dicalcium silicate, so that the slurry with the mass concentration of $68 \%$ had a slower hydration rate than the slurries with mass concentrations of $56 \%$ and $62 \%$. Thus, the $\mathrm{T}_{2}$ spectrum of the filling slurry with the mass concentration of $68 \%$ changed slightly.

From the reaction equation of $\mathrm{MgO}$, it can be seen that the higher the mass concentration of the slurry, the more the $\mathrm{MgO}$ content in the filling slurry, so $\mathrm{MgO}$ has the fastest chemical reaction, and more $\mathrm{MgO}$ crystals were produced. Therefore, the $\mathrm{T}_{2}$ distribution curve of the slurry with the mass concentration of $68 \%$ was closer to the left side.

(2) With the decrease in the cement-sand ratio, the left moving speed of the $T_{2}$ curve gradually reduced; that is, the hydration process gradually became slower. Compared with the pore-level statistics of the three different cement-sand ratios, as the degree of hydration increased, the smaller the ratio of cementsand became, the slower the increasing speed of the harmless pores and less harmful pores was. This may be because, with a reduction in the cement-sand ratio, the hydration reaction gradually proceeded toward the hydration reaction of dicalcium silicate. When the cement-sand ratio was $1: 3$, the hydration reaction was dominated by the hydration of tricalcium silicate. When the cement-sand ratio was $1: 8$, the hydration reaction was dominated by the hydration of dicalcium silicate. In addition, the $\mathrm{Ca}(\mathrm{OH})_{2}$ crystals produced by the hydration reaction of tribasic calcium silicate were smaller than those generated by the hydration reaction of dicalcium silicate. Therefore, the change in the harmless pores and less harmful pores was small.

(3) The pore size distribution of the filling slurry varied greatly in the early stage, mainly owing to the pore size being dominated by harmful pores and the high fluidity of the internal pore water, which increased the rate of the hydration reaction. As the hydration process progressed, the harmful pores were gradually transformed into less harmful pores and harmless pores, and the size of the less harmful pores and harmless pores reduced, thus binding the flow of internal pore water and slowing down the hydration reaction rate. As a result, the pore size distribution in the later stage changed less.

\section{Conclusions}

(1) The higher the mass concentration of the filling slurry, the smaller the pore size of the filling slurry and the smaller the change in the $\mathrm{T}_{2}$ spectrum area, which indicates that the hydration reaction rate is slower. At the same time, the higher the mass concentration, the higher the proportion of harmless pores and less harmful pores. Furthermore, the spectrum area of the filling slurry with the mass concentration of $62 \%$ is the largest.

(2) The larger the cement-sand ratio of the filling slurry, the smaller the pore size of the filling slurry. The smaller the cement-sand ratio, the higher the proportion of harmful pores in the filling slurry. The $T_{2}$ spectral area of the filling slurry with the cement-sand ratio of $1: 8$ is the largest, indicating the porosity of the filling slurry with the cement-sand ratio of $1: 8$ is the largest. With a decrease in the cement-sand ratio, the proportion of harmless pores and less harmful pores decreases and the proportion of harmful pores increases.

(3) The reaction rate of the filling slurry is fast in the first $3 \mathrm{~d}$, and the pore distribution changes, but it tends to become stable after $7 \mathrm{~d}$. From the perspective of the proportion of harmful pores and the multiharmful pores, it can be analysed that the higher the concentration of the filling slurry and the greater the value of the cement-sand ratio, the higher the compressive strength of the tailing filling slurry.

\section{Data Availability}

The data used to support the findings of this study are available from the corresponding author upon request.

\section{Conflicts of Interest}

The authors declare that there are no conflicts of interest.

\section{Acknowledgments}

The authors gratefully acknowledge the financial support of the National Natural Science Foundation of China (no. 41502327), National Major Scientific Instruments and Equipment Development Projects (no. 2013YQ17046310), and Fundamental Research Funds for the Central Universities of Central South University (no. 2017zzts795). In addition, the authors are also grateful to Songtao Yu and Lin Huang for helping with language editing.

\section{References}

[1] L. Li, "Generalized solution for mining backfill design," International Journal of Geomechanics, vol. 14, no. 3, article 04014006, 2013.

[2] T. Belem and M. Benzaazoua, "Design and application of underground mine paste backfill technology," Geotechnical and Geological Engineering, vol. 26, no. 2, p. 175, 2008.

[3] T. Blackman and R. Blackman-Woods, "Experimental characterization of the stress-strain behaviour of cemented paste backfill in compression," Journal of Materials Science, vol. 42, no. 11, pp. 3914-3922, 2007.

[4] B. Han, A. Wu, Y. Wang et al., "Optimization and application of cemented hydraulic fill (CHF) with low strength aggregate and extra fine grain full tailings," Journal of Central South University, vol. 43, no. 6, pp. 2357-2362, 2012.

[5] J. Fu, C. Du, and W. Song, "Strength sensitivity and failure mechanism of full tailings cemented backfills," Journal of University of Science and Technology Beijing, vol. 36, no. 9, pp. 1149-1157, 2014. 
[6] X. Ke, X. Zhou, X. Wang et al., "Effect of tailings fineness on the pore structure development of cemented paste backfill," Construction and Building Materials, vol. 126, pp. 345-350, 2016.

[7] S. Ouellet, B. Bussière, M. Aubertin et al., "Characterization of cemented paste backfill pore structure using SEM And IA analysis," Bulletin of Engineering Geology and the Environment, vol. 67, no. 2, pp. 139-152, 2008.

[8] X. Huang, X. Zhao, S. Bie et al., "Hardening performance of phosphogypsum-slag-based material," Procedia Environmental Sciences, vol. 31, pp. 970-976, 2016.

[9] F. I. El-Hosiny, "Hydration and pore structure characteristics of superplasticized hardened slag cement pastes," Ceramics Silikaty, vol. 46, no. 2, pp. 63-67, 2002.

[10] K. A. Khalil, "Pore structure and surface area of hardened cement pastes containing silica fume," Materials Letters, vol. 26, no. 4-5, pp. 259-264, 1996.

[11] Z. Xu, Y. Yang, J. Chai et al., "Mesoscale experimental study on chemical composition, pore size distribution, and permeability of tailings," Environmental Earth Sciences, vol. 76, no. 20, p. 707, 2017.

[12] A. She, Relationship between the State of Water in Cement Slurry and the Hydration Process and Microstructure of Slurry, Tongji University, Shanghai, China, 2011.

[13] L. Yu and J. Chen, "A new evolution model of concrete porosity under continuous hydration," International Journal of Modelling Identification and Control, vol. 26, no. 4, p. 345, 2016.

[14] J. Liu, R. Wu, A. Wu et al., "Bleeding characteristics and improving mechanism of self-flowing tailings filling slurry with low concentration," Minerals, vol. 7, no. 8, p. 131, 2017.

[15] B. Koohestani, A. Koubaa, T. Belem et al., "Experimental investigation of mechanical and microstructural properties of cemented paste backfill containing maple-wood filler," Construction and Building Materials, vol. 121, pp. 222-228, 2016.

[16] J. Huang, K. Xu, S. Guo et al., "Comprehensive study on structures of shale reservoirs based on SEM, NMR and X-CT," Geoscience, vol. 29, no. 1, pp. 198-205, 2015.

[17] J. Li, K. Zhou, W. Liu et al., "NMR research on deterioration characteristics of microscopic structure of sandstones in freeze-thaw cycles," Transactions of Nonferrous Metals Society of China, vol. 26, no. 11, pp. 2997-3003, 2016.

[18] Y. Yao, D. Liu, Y. Cai et al., "Advanced characterization of pores and fractures in coals by nuclear magnetic resonance and X-ray computed tomography," Science China Earth Sciences, vol. 53, no. 6, pp. 854-862, 2010.

[19] L. Liu, Z. Fang, C. Qi et al., "Experimental investigation on the relationship between pore characteristics and unconfined compressive strength of cemented paste backfill," Construction and Building Materials, vol. 179, pp. 254-264, 2018.

[20] Test Method for Strength of Hydraulic Cement Mortar; Chinese National Standard: GB/T 17671-1999, State Bureau of Quality and Technical Supervision, Beijing, China, 1999.

[21] D. Lanigan, P. A. McLean, B. Curran et al., "Comparison of low-field NMR and mercury intrusion porosimetry in characterizing pore size distributions of coals," Fuel, vol. 95, no. 1, pp. 152-158, 2012.

[22] H. Li, B. Lin, W. Yang et al., "Experimental study on the petrophysical variation of different rank coals with microwave treatment," International Journal of Coal Geology, vol. 154, pp. 82-91, 2016.

[23] H. Kim, Y. Han, and J. Park, "Evaluation of permeable pore sizes of macroporous materials using a modified gas permeation method," Materials Characterization, vol. 60, no. 1, pp. 14-20, 2009.

[24] Y. Han, H. Kim, and J. Park, "Fabrication and characterization of macroporous flyash ceramic pellets," Materials Characterization, vol. 62, no. 9, pp. 817-824, 2011.

[25] H. Fu, X. Wang, L. Zhang et al., "Investigation of the factors that control the development of pore structure in lacustrine shale: a case study of block X in the Ordos Basin, China," Journal of Natural Gas Science and Engineering, vol. 26, pp. 1422-1432, 2015.

[26] Y. Yao, D. Liu, Y. Che et al., "Petrophysical characterization of coals by low-field nuclear magnetic resonance (NMR)," Fuel, vol. 89, no. 7, pp. 1371-1380, 2010.

[27] H. Li, J. Zhu, and H. Guo, "Methods for calculating pore radius distribution in rock from NMR $\mathrm{T}_{2}$ spectra," Chinese Journal of Magnetic Resonance, vol. 25, no. 2, pp. 273-280, 2008.

[28] C. Liu, H. Deng, Y. Wang et al., "Time-varying characteristics of granite microstructures after cyclic dynamic disturbance using nuclear magnetic resonance," Crystals, vol. 7, no. 10, p. 306, 2017.

[29] S. Xie, Y. Yao, J. Chen et al., "Research of micro-pore structure in coal reservoir using low-field NMR," Journal of China Coal Society, vol. 40, pp. 170-176, 2015.

[30] Z. Wu, "An approach to the recent trends of concrete science and technology," Journal of the Chinese Ceramic Society, vol. 7, pp. 262-270, 1979.

[31] L. Wang, Building Materials Science, China Water and Power Press, Beijing, China, 2nd edition, 2008.

[32] D. Jansen, F. Goetz-Neunhoeffer, B. Lothenbach et al., "The early hydration of Ordinary Portland Cement (OPC): an approach comparing measured heat flow with calculated heat flow from QXRD," Cement and Concrete Research, vol. 42, no. 1, pp. 134-138, 2012.

[33] K. L. Scrivener, P. Juilland, and P. J. M. Monteiro, "Advances in understanding hydration of Portland cement," Cement and Concrete Research, vol. 78, pp. 38-56, 2015.

[34] C. Unluer and A. Al-Tabbaa, "Enhancing the carbonation of $\mathrm{MgO}$ cement porous blocks through improved curing conditions," Cement and Concrete Research, vol. 59, no. 10, pp. 55-65, 2014.

[35] S. Ruan and C. Unluer, "Influence of mix design on the carbonation, mechanical properties and microstructure of reactive $\mathrm{MgO}$ cement-based concrete," Cement and Concrete Composites, vol. 80, pp. 104-114, 2017.

[36] Y. Zhou, H. Deng, and J. Liu, "Rational utilization of fine unclassified tailings and activated blast furnace slag with high calcium," Minerals, vol. 7, no. 4, p. 48, 2017.

[37] H. Yan, Civil Engineering Materials, Tongji University Press, Shanghai, China, 2nd edition, 2010. 


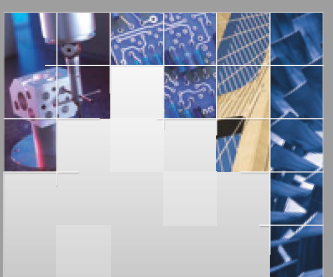

\section{Enfincering}
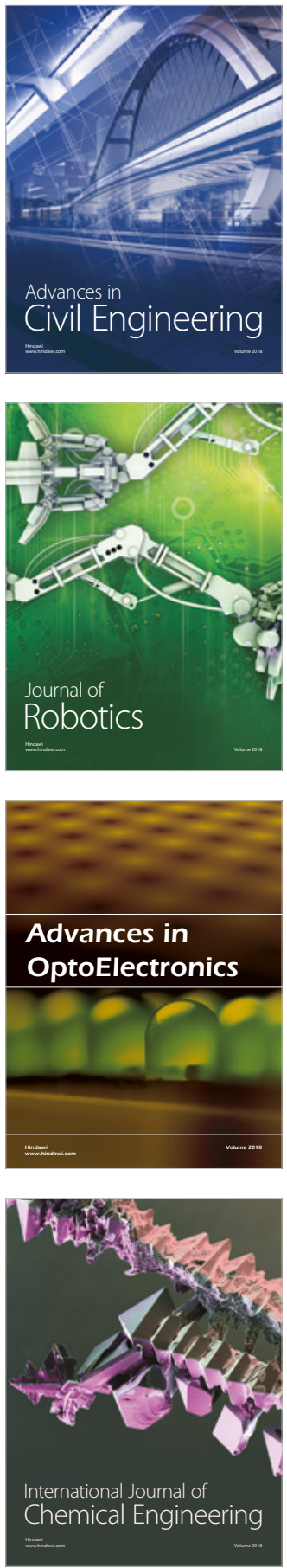

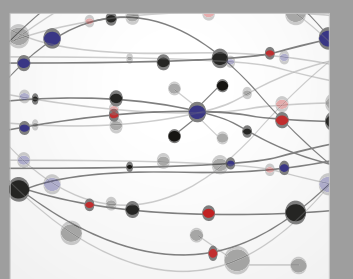

\section{Rotating \\ Machinery}

The Scientific World Journal

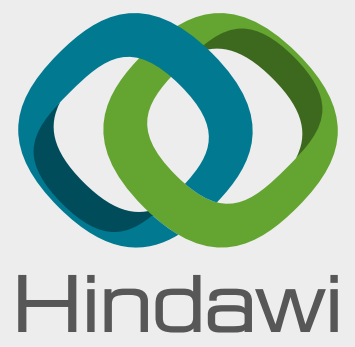

Submit your manuscripts at

www.hindawi.com
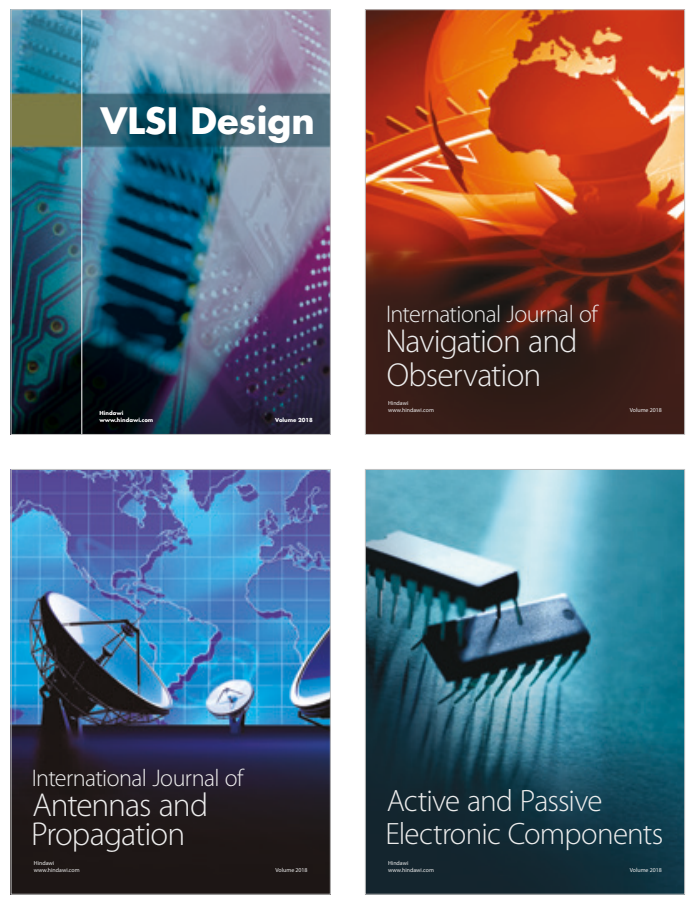
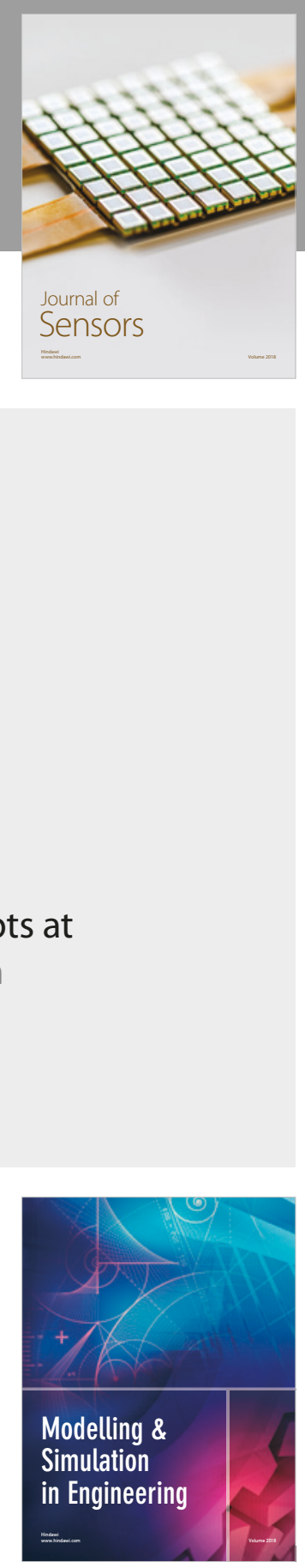

\section{Advances \\ Multimedia}
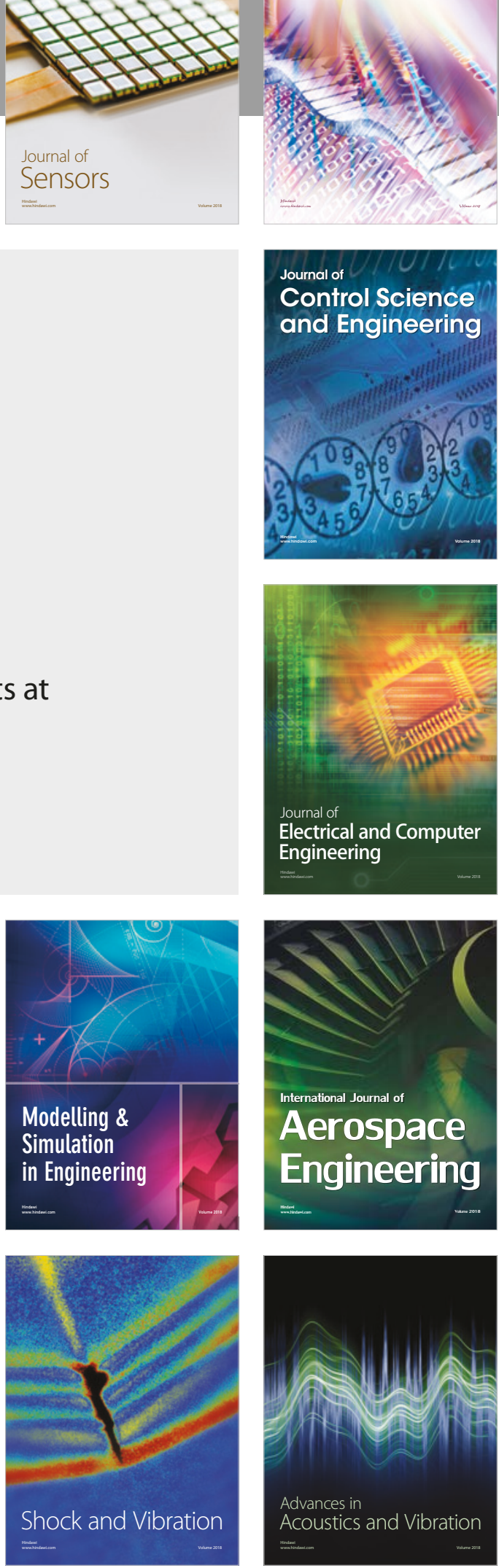